\title{
A new middle Cambrian trilobite with a specialized cephalon from Shandong Province, North China
}

\author{
Zhixin Sun, Han Zeng, and Fangchen Zhao \\ Acta Palaeontologica Polonica 65 (4), 2020: 709-718 doi:https://doi.org/10.4202/app.00753.2020
}

Trilobites achieved their maximum generic diversity in the Cambrian, but the peak of morphological disparity of their cranidia occurred in the Middle to Late Ordovician. Early to middle Cambrian trilobites with a specialized cephalon are rare, especially among the ptychoparioids, a group of libristomates featuring the so-called "generalized" bauplan. Here we describe an unusual ptychopariid trilobite Phantaspis auritus gen. et sp. nov. from the middle Cambrian (Miaolingian, Wuliuan) Mantou Formation in the Shandong Province, North China. This new taxon is characterized by a cephalon with an extended anterior area of double-lobate shape resembling a pair of rabbit ears in later ontogenetic stages; a unique type of cephalic specialization that has not been reported from other trilobites. Such a peculiar cephalon as in Phantaspis provides new insights into the variations of cephalic morphology in middle Cambrian trilobites, and may represent a heuristic example of ecological specialization to predation or an improved discoidal enrollment.

Key words: Trilobita, Ptychopariida, ontogeny, specialization, Miaolingian, Paleozoic, Longgang, Asia.

Zhixin Sun [zxsun@nigpas.ac.cn], Han Zeng [hzeng@ nigpas.ac.cn], and Fangchen Zhao [fczhao@nigpas.ac.cn] (corresponding author), State Key Laboratory of Palaeobiology and Stratigraphy, Nanjing Institute of Geology and Palaeontology and Center for Excellence in Life and Palaeoenvironment, Chinese Academy of Sciences, Nanjing 210008, China; University of Chinese Academy of Sciences, Beijing 100049, China.

This is an open-access article distributed under the terms of the Creative Commons Attribution License (for details please see creativecommons.org), which permits unrestricted use, distribution, and reproduction in any medium, provided the original author and source are credited. 
FoF 